\title{
MISTURADOR AUTOMÃTICO PARA MOTORES A GÁS
}

\section{Armando Foá}

Fâa o bom e regular funcionamento de um motor de carburação é necessário, entre outras cousas, uma dosagem boa e regular das proporções do ar e do combustível na mistura que vai ser queinada.

No caso dos motores a gasolina, como é sabido, usa-se o carburador, - qual, automàticamente, laz com que a uma variação da quantidade de ar corresponda uma variação da quantidade de combustível, no mesmo sentido e, tanto quanto possível, proporcional. Observamos que entra em jôgo no carburador, um princípio físico e não um dispositivo mecânico. Por outras palavras, o ar, passando no aparelho, arrasta uma correspondente quantidade de combustível, em virtude da depressão produzida na garganta do cano de aspiração.

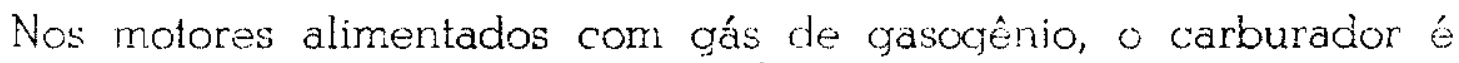
substituido por outro órgão, o misturador. Na sua forma mais generalizada, o misturador não passa, em essência, de um tubo em forma de T, no quả entram, de um lado, o gás, e, do outro, o ar. O tronco central, em que se forma a mistura, liga-se à canalização de admissão do motor. Nas entradas do gás e do ar, estão inseridas duas válvulas, cujo funcionamento regula a potência do motor. Em geral, os comandos das duas válvulas estão mecânicamente ligados, de maneira que a cada posição de una delas corresponde uma posiça deteminada da outra.

Para motores a gás de gasogênio, um tal sistema é, a nosso ver, un tanto sem fundamento: fazer depender a vazão do gás (ou do ar) sòmeste da posição da válvula correspondente, não é lógico. De-fato. os dois !luidos encontram, antes de chegar ao misturador, resislências diferentes, as quais, a-de-mais, dependem de modo bastante complexo da intensidade da suç̧ão do motor. Assim, deven-se introduzir comandos suplementares. O uso dêstes, porém, acarreta o inconveniente de se deixar apenas ao "ouvido" do motorista o julgar da mistura, isto é, se está sendo realizada em proporções convenientes ou não.

Para se eliminar tal estado de cousas, o único recurso é a adoção de um meio físico para controlar a dosagem. A vazão de um dos dois fluidos, por exemplo a do qás, é que deve automàticamente regular a do outro fluido. 
Tendo em vista êste melhoramento, imaginamos um tipo de misturador, representado na figura 1 .

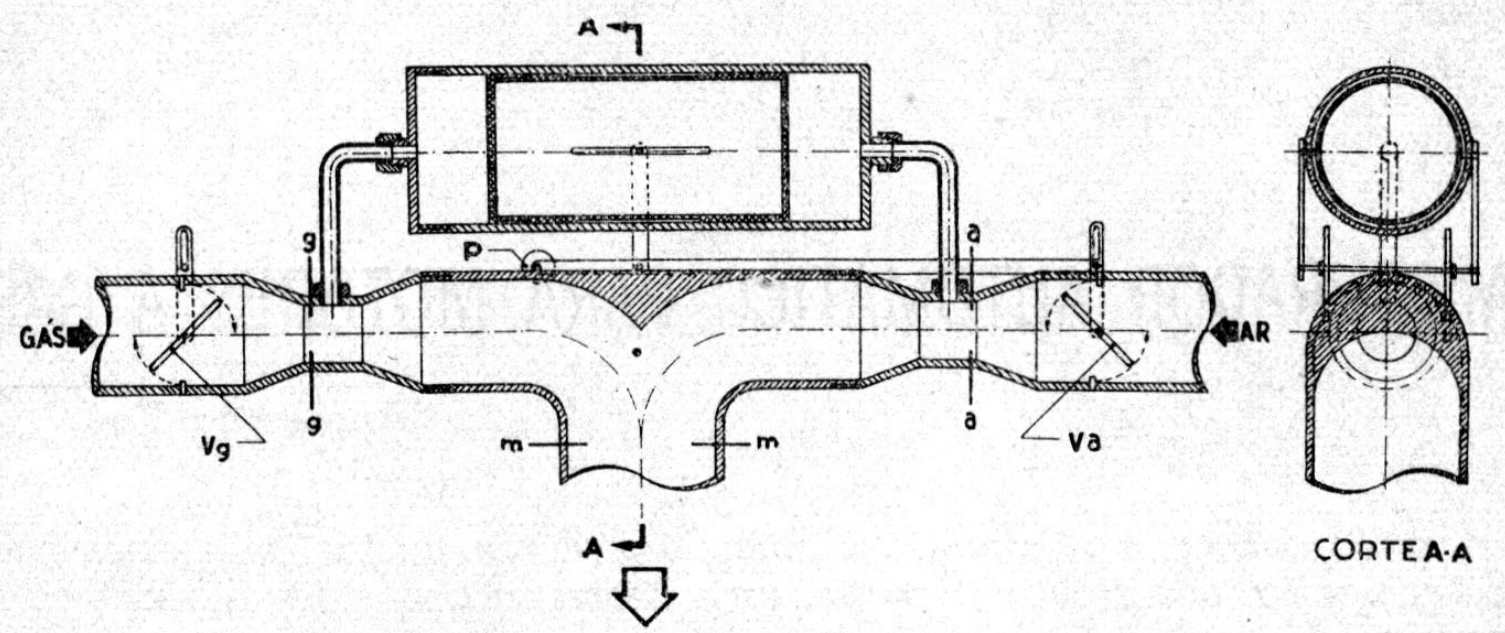

Fig. 1

- misturador por nós idealizado conserva a forma clássica em T. Traz, porém, em cada um dos dois troncos laterais, um gargalo. Como se vê na figura 1, o misturador é simétrico, correspondendo ao caso em que os dois fluidos, tendo igual densidade, devem ser misturados nas proporções de 1 para 1 .

Chamando $p_{m}, p_{g}$ e $p_{a}$ às pressões nas três secções $m-m, g-g$ e a-a (indicadas na fig. 1), por $Q_{\mathrm{g}} \in \mathrm{Q}_{\mathrm{a}}$ às vazões do gás e do ar, respectivamente, e por $k_{\mathbf{g}}$ e $k_{\mathrm{a}}$ dois coeficientes numéricos, podemos escrever:

$$
\begin{aligned}
& Q_{\mathrm{g}}=\mathrm{k}_{\mathrm{g}} \sqrt{\mathrm{pm}_{\mathrm{m}}-\mathrm{p}_{\mathrm{g}}} \\
& \mathrm{Q}_{\mathrm{a}}=\mathrm{k}_{\mathrm{a}} \sqrt{\mathrm{pm}_{\mathrm{m}}-\mathrm{p}_{\mathrm{a}}}
\end{aligned}
$$

Admitindo ainda que as viscosidades dos dois fluidos sejam iguais, resultarão também iguais os dois coeficientes $\mathrm{k}_{\mathrm{g}}$ e $\mathrm{k}_{\mathrm{a}}$. Assim, $\mathrm{Q}_{\mathrm{g}}$ será igual a $Q_{a}$ quando $p_{m}-p_{g}=p_{m}-p_{a}$, ou seja quando $p_{g}=p_{a}$. A regulação do aparelho consistirá em se obter pela variação da pressão pg (por efeito da manobra da válvula $\mathrm{v}_{\mathrm{g}}$ ), variação automática da pressão $\mathrm{pa}_{\mathrm{a}}$ (através do movimento da válvula $\mathrm{v}_{\mathrm{a}}$ ) até igualar $\mathrm{p}_{\mathrm{g}}$.

Isto se obtem por meio do dispositivo superior, um pequeno pistão, móvel num cilindro. As duas faces do pistão estão sujeitas, por meio de dois tubos, às pressões $\mathrm{p}_{\mathrm{g}}$ e $\mathrm{p}_{\mathrm{a}}$, de forma que, quando as duas pressões não são iguais, o pistão mover-se-á para a direita ou para a esquerda, conforme for $\mathrm{p}_{\mathrm{a}}<\mathrm{p}_{\mathrm{g}}$ ou $\mathrm{p}_{\mathrm{a}} \mathrm{p}_{\mathrm{g}} .>$

Suponhamos que o motor esteja funcionando sob determinada condição. Querendo aumentar-lhe a potência; será necessário abrir mais (mecânicamente) a válvula $\mathrm{v}_{\mathrm{g}}$. Em virtude do aumento de $Q_{\mathbf{g}}$, aumentará a diferença $\mathrm{p}_{\mathrm{m}}-\mathrm{p}_{\mathrm{g}}$. Por outro lado, aplicando o princípio de Bernouilli, $\mathrm{p}_{\mathrm{g}}<\mathrm{p}_{\mathrm{m}}$, o que significa que ao aumento de $Q_{\mathrm{g}}$ corresponderá diminuição de $\mathrm{p}_{\mathrm{g}}$ e por isto o pistão será levado para a esquerda. Inversamente, fechando a válvula $\mathbf{v}_{\mathbf{g}}$, o pistão irá para a direita. 
$\grave{A}$ abertura (ao fechamento) da válvula $\mathrm{v}_{\mathrm{g}}$ deve corresponder, para manter a regular dosagem da mistura, a abertura (ou o fechamento) da válvula $v_{a}$.

Resumindo, o movimento do pistão deverá comandar a válvula $\mathrm{v}_{\mathrm{a}}$, no sentido de abríla ou fechá-la, conforme o movimento do pistão, for para a esquerda ou para a direita.

O sistema de comando está claramente representado na figura 1: os dois eixos ligados ao pistão de um lado e do outro, passam através das duas aberturas feitas nas geratrizes correspondentes do cilindro externo. P representa um contrapêso de chumbo, por exemplo, destinado a equilibrar o pêso do tirante, de maneira a não introduzir distorções no movimento do pistão.

É evidente que o cilindro deve estar em posição horizontal, pois, de outra f́rmá, o pêso do pistão acionaria o mecanismo. Na estrada rıão será sempre assirn, mas pensamos que isto não constituirá um grave inconveniente, uma vez que o pistão seja bastante leve. O seu pêso não será capaz de vencer as resistências mecânicas que se opõem ao comando da válvula $\mathrm{v}_{\mathrm{a}}$.

Queremos ainda observar que o pistão deve ter um comprimento tal que, em nenhuma posição, se possa estabelecer a comunicação através dos orifícios no cilindro, entre uma das duas câmaras do cilindro e o ambiente externo.

Quanto à sensibilidade do aparelho, é evidente que será tanto maior quanto maior for o pêso do pistão, e quanto maior o diâmetro dêste, pois a força ativa é proporcional ao produto da área pela diferença entre as duas pressões $p_{\mathrm{g}}$ e $p_{\mathrm{a}}$.

O caraterístico essencial do aparelho é ser: automático. Durante o funcionamento de um gasogênio, como se sabe, as resistências dos filtros vão aumentando. Em consequência disto, para determinada posição da válvula $v_{\mathrm{g}}$, há diminuição progressiva de $Q_{\mathrm{g}}$. Êste efeito equivāle a um fechamento da válvula $\mathrm{v}_{\underline{\underline{g}}}$ e, por isso, o aparelho, fechando automàticamente a válvula $\mathrm{v}_{\mathrm{a}}$, deveria manter uma mistura uniforme, evitando a contínua manobra da válvula de ar, inconveniente bem conhecido a quem quia veículos a gasogênio.

Repetimos: $O$ aparelho desenhado aplica-se para o caso de dois fluidos de igual densidade e viscosidade, que devam ser misturados nas proporções de 1 para 1, que é mais ou menos o caso dos motores a gás de gasogênio. De-fato, a densidade e a viscosidade do gás produzido por um gasogênio são aproximadamente iguais às do ar. Além disso, um volume de gás precisa, para a sua combustão completa, de cêrca de um volume de ar.

O aparelho pode ser modificado de maneira a corresponder melhor às exigências particulares. Para cada gasogênio, de-fato, pode ser determinada a composição média de gás que êle produz, a qual permite calcular a sua densidade e a quantidade de ar necessária para a com. bustão completa de uma determinada quantidade de gás, e assim variar correspondentemente a relação entre as áreas das secções a-a e g-g 
Depreende-se, assim, que a dosagem da mistura será a ótima nuna determinada condição de funcionamento. Afastando-se desta, a dosagem não mais será perfeita, pois a lei de variação da vazão sob a pressão não será exatamente a mesma para os dois gases a serem misturados. t́ - que acontece também com o carburador dos motores a gasolina. E achamos que se terá conseguido um resultado útil se se puder obter uma dosagem perfeita em condições normais de funcionamento do motor, e uma boa dosagem, se não períeita, sob outras condições.

Infelizmente, ainda não nos foi possível verificar pràticamente o comportamento de um tal aparelho, pelo que nos restringimos a indicar o seu princípio de funcionamento. É nossa intenção construir um, e efetuar com êle experiências sistemáticas, cuios resultados serão relatados futuramente. 